\title{
Ecological Innovation: Biomimicry as a New Way of Thinking and Acting Ecologically
}

\author{
Vincent Blok ${ }^{1} \cdot$ Bart Gremmen $^{1}$
}

Accepted: 28 December 2015/Published online: 7 January 2016

(C) The Author(s) 2016. This article is published with open access at Springerlink.com

\begin{abstract}
In this article, we critically reflect on the concept of biomimicry. On the basis of an analysis of the concept of biomimicry in the literature and its philosophical origin, we distinguish between a strong and a weaker concept of biomimicry. The strength of the strong concept of biomimicry is that nature is seen as a measure by which to judge the ethical rightness of our technological innovations, but its weakness is found in questionable presuppositions. These presuppositions are addressed by the weaker concept of biomimicry, but at the price that it is no longer possible to distinguish between exploitative and ecological types of technological innovations. We compare both concepts of biomimicry by critically reflecting on four dimensions of the concept of biomimicry: mimesis, technology, nature, and ethics.
\end{abstract}

Keywords Biomimicry - Ecological innovation - Mimesis · Nature as measure · Technological innovation

\section{Introduction}

Because of growing pressures on resources and the environment, it is increasingly acknowledged that we have to look for alternatives for the ecosystem destructing technologies of the industrial age (cf. European Commission 2012). Consequently, the demand for recyclable and biodegradable materials is increasing. In the context of the European Union for instance, it is argued that "in a world with growing pressures on resources and the environment, the EU has no choice but to go for the

Vincent Blok

info@vincentblok.nl; vincent.blok@wur.nl

1 School of Social Sciences, Wageningen University, Hollandseweg 1, 6707, KN, Wageningen, The Netherlands 
transition to a resource-efficient and ultimately regenerative circular economy" (European Commission 2012: 1).

Over the years, biomimetic approaches to technology and innovation have increasingly received attention as such an alternative for the ecosystem destructing technologies of the industrial age. Biomimicry or biomimetics is "a new science that studies nature's models and then imitates or takes inspiration from these designs and processes to solve human problems" (Benyus 2002: I). Nature is seen here as an inspiring source of knowledge — a solar cell inspired by a leaf for instance-which enables nature-based innovations such as recyclable and biodegradable materials. Other examples include sustainable buildings inspired by self-cooling mounds of termites or car design inspired by the way trees and bones optimize their strength and materials.

According to the proponents of biomimicry, it introduces a new and ecosystemfriendly approach to nature, which is no longer characterized by the domination and exploitation of nature, but by learning and exploration. Benyus for instance argues that the first industrial revolution is characterized by the domination and exploitation of nature, whereas the second-biomimetical-industrial revolution is characterized by learning from, and exploring, nature. By 'doing it the natural way', our technological innovations can claim to be better embedded in, and in harmony with, the natural ecosystems of planet earth (Benyus 2002; cf. Hawken et al. 2000). A similar orientation can be found in McDonough and Braungart's Cradle to Cradle approach:

Rather than asking, "How do I meet today's environmental standards?" designers would begin to ask, "How do my design decisions make sense in the overarching context of the natural world?" Ironically, this focus on the earth takes the green out of green design, for following the laws of nature is simply the path to good, high-quality design. In the natural world, the processes of each organism in a living system contribute to the health of the whole. One organism's waste is food for another and nutrients and energy flow perpetually in closed-loop cycles of growth, decay and rebirth. Understanding these regenerative qualities empowers us to recognize that all the materials we use as designers-even highly technical, synthetic materials - can also be seen as nutrients. ... The laws of nature are the bedrock of good design. And they inform a cohesive set of science-based design practices, which we call Cradle to Cradle Design (McDonough \& Braungart 2002).

According to the opponents of biomimicry however, the concept is so loose that one might wonder whether it is more than a slogan forged by chemists in order to play a role in the field of sustainability (cf. Bensaude-Vincent et al. 2002). They doubt that biomimicry is a real revolution, and wonder whether it is able to achieve its ambitions and under which conditions. If the current discussion about the potentiality of biomimicry as a new way of thinking and acting ecologically shows one thing, it is that the concept itself and its implications are philosophically underdeveloped (cf. Mathews 2011). This is an important omission, because it is possible that biomimicry is implicitly conceptualized in ambiguous ways or in categories - technology versus 
nature, discovery versus intervention, (technological) exploitation versus (ecological) exploration, and so on-that hinder its own development.

In order to explore the conceptualization of biomimicry as an ecological form of technological innovation, we critically reflect on the concept in this article. In "Introduction" section, we analyze the elements that constitute the concept of biomimicry and its philosophical origin: nature and mimesis. We distinguish a strong and a weaker, but more sophisticated, concept of biomimicry. In "Two Concepts of Biomimicry" section, we compare both concepts of biomimicry by critically reflecting on four dimensions of the concept of biomimicry: mimesis, technology, nature, and ethics.

\section{Two Concepts of Biomimicry}

\section{Biomimicry and the Conceptualization of Nature}

The first question we would like to address concerns the way the concept of nature is presupposed in the literature on biomimicry. During the past decades, several philosophers and scientists have conceptualized nature in their work on biomimicry. According to Philip Ball, consultant editor of Nature, biomimetics "decodes and elucidates the cell's molecular machinery piece by piece" (Ball 2001: 413); this means that nature is understood here already in a technological way, i.e., as a machine. This idea is confirmed by the materials chemist Julian Vincent, who conceptualizes nature as "4 billion years' worth of R\&D” (Vincent 2001: 321). In a similar vein, Benyus argues that nature "has already solved the problems we are struggling to solve" in a process of " 3.8 billion years of research and development" (Benyus 2002. Nature is seen here as a huge R\&D lab. In a historical study of the concept of biomimicry, Bensaude-Vincent et al. even argue that nature is seen as an engineer in biomimetic practices: "Biologists, chemists, physical chemists, and engineers are reunited around a common problem: how can we create, develop, maintain and, eventually, recycle a functional structure with optimal properties? They started to consider nature as an artist, an incomparable engineer from whom we can learn many lessons" (Bensaude-Vincent et al. 2002: 2). In the literature on biomimicry, nature is therefore seen as an engineer who is involved in an enduring $\mathrm{R} \& \mathrm{D}$ program in order to solve natural problems.

It is striking that the ambition of biomimicry is to mimic nature, but that nature is in fact already understood in technological terms-i.e., as "natural technology" (Vincent and Mann 2002) - and biomimicry as technology transfer from nature to man (Bensaude-Vincent et al. 2002). We encounter a first ambiguity here regarding the concept of nature. On the one hand, the concept of nature is rooted in a technological concept of nature: natural technology or nature as artist, tektoon, techne, technology. On the other hand, the traditional dichotomy between nature and technology is ignored in biomimetical approaches, or, as Ball puts it, in biomimetical methods of technology and innovation, "this disparity between the natural and synthetic art of manufacture begins to diminish" (Ball 2001: 413). We recognize the Marxist position in this line of thought, which argues that all human 
technology is embedded in nature and therefore an expression of nature, whether it is sustainable or not. This first ambiguity raises two questions. On the one hand, it is questionable whether it is possible to overcome fundamental dichotomies like the one between nature and technology, which is so deeply rooted in our culture and reinvigorates public debates about genetic modification in food production, human enhancement, and so on (Bensaude-Vincent et al. 2002). On the other hand, and more important for our current discussion, is the question of what in the end is the difference between the first and the second industrial revolution if the disparity between nature and technology begins to diminish? Given the claim of the proponents of biomimicry that it entails a new approach to technology and innovation that is embedded in nature and in harmony with the natural ecosystems of planet earth, it is at least striking that the mimicking of nature is in fact mimicking a technological model of nature.

The ambiguity between nature and technology in biomimicry is not only at stake in current research; it is also rooted in the philosophical tradition. In his Physics, for instance, Aristotle explores the concept of nature. Here also however, Aristotle is using examples from the domain of the techne-the vase, the statue-to understand phusis. In the third chapter of book three for instance, Aristotle introduces four causes of natural beings as essential constituents of their physical change (Aristotle 194b20-25). However, in exploring the four causes of natural beings, he uses technological examples like the bronze of the statue as an example of the material cause, the interval between two notes as an example of the formal cause, the craftsman who makes the statue as an example of the efficient cause, and exercising for the sake of health as an example of the final cause (Aristotle 1980: 194b25-35). This means that Aristotle's concept of nature in fact presupposes a technological understanding of nature.

This also becomes clear in Aristotle's equation of technology with nature in his Physics. According to Aristotle, both technology (techne) and nature (phusis) are seen as productive (poiesis). The difference between techne and phusis is that natural beings have the principle of their productivity in themselves, whereas artefacts are produced by an external agent such as an artist or engineer (Aristotle 192b8-34); techne is human production or poiesis by an external agent and phusis is natural production or self-making (auto-poiesis). Because both techne and phusis are rooted in poiesis, both are essentially the same according to Aristotle (cf. Aristotle 199a10-20). ${ }^{1}$ However, the decision to think of nature in terms of poiesis already implies that nature is understood in technological terms, namely, in terms of its productivity or makeability (cf. Heidegger 1999: 88).

The first conclusion we can draw, therefore, is that the identity of techne and phusis in the Aristotelian tradition can be seen as the philosophical origin of the technological conceptualization of nature in the literature on biomimicry. Both the Aristotelian tradition and current biomimetic research presuppose a technological concept of nature and are therefore incapable of conceptualizing nature qua nature (see "Two Concepts of Biomimicry" section).

\footnotetext{
1 In the next section, we explore an additional argument as to why, according to Aristotle, nature and technology are essentially the same.
} 


\section{Biomimicry and the Conceptualization of Mimesis}

We leave now for a moment the technological concept of nature which is presupposed in Aristotle's philosophy, and turn to the way he explicitly conceptualized the relation between techne and phusis. The reason for this is that in Aristotle's Physics, we can also find the classical definition of the concept of mimesis. According to Aristotle, techne and phusis are essentially the same not only because both are rooted in poiesis (cf. section 1.1), but also because technology mimics nature (Aristotle 194a20-25). The techne either-on the basis of the phusis-accomplishes or perfects what phusis is not capable of effectuating itself, or imitates (mimeitai-mimesis) phusis (Aristotle 199a20-25). There are, therefore, two types of the technological mimesis of nature according to Aristotle. First of all, there is the mimetic copy or reproduction of the naturally given, which we could call the naturalistic concept of mimicry with which we are familiar. It is, however, important to acknowledge that Aristotle distinguishes also another type of mimesis, which is based on the deficiency of nature. Nature is not capable of producing or effectuating everything, and, in this case, mimicry productively supplements the capabilities of nature (cf. Lacoue-Labarthe 1998). Which one of both types of mimesis is used in the literature on biomimicry and which of both types is suitable to be used in the second-biomimetic-industrial revolution?

According to some proponents of biomimicry, mimicry is not the exploitation of biomaterials for technological applications, but consists in learning from and exploring nature (cf. Benyus 2002). Biomimetical scientists try to "elucidate how life creates complex hierarchical structures, integrating many functions, to understand chemical and physical strategies employed by living systems in order to apply them, with suitable modifications, to the field of technological design" (Bensaude-Vincent et al. 2002: 2). Rather than inventing new technologies, biomimicry discovers natural processes and applies these processes in our technological design. Can we claim that Benyus cum suis opt for biomimicry as a copy or reproduction of natural processes and that they therefore embrace the naturalistic concept of biomimicry? In fact, we have to distinguish between a strong and a weaker concept of biomimicry.

The strong concept of biomimicry is represented by Janine Benyus. She conceptualizes biomimicry in a naturalistic way as imitation of nature's models in order to solve human problems. The main objective of biomimicry is to "echo" the ideas of nature in our own lives: biomimetic scientists "are exploring nature's masterpieces-photosynthesis, self-assembly, natural selection, self-sustaining ecosystems, eyes and ears and skin and shells, talking neurons, natural medicines, and more-and then copying these designs and manufacturing processes to solve our own problems. I call their quest biomimicry - the conscious emulation of life's genius. Innovation inspired by nature" (Benyus 2002: 4-5). Although mimicry is inspired by nature, this inspiration is primarily understood as discovery and imitation of nature and represents therefore the naturalistic concept of mimicry that we find in Aristotle's Physics.

This strong concept of biomimicry is, according to Benyus, partly motivated by the idea that nature is a measure to judge the ethical rightness of our technological 
innovations (Benyus 2002). Because natural principles are assumed to be principles that conduce to ecological health and integrity of the ecosystems of planet earth, biomimetic technology and innovation can claim to be ethically right. ${ }^{2}$ By using the same design principles as natural entities and systems, and by modelling our technological design on natural principles, biomimicry adheres to a bioinclusive ethics that enables us to resituate our technological design within the ecological limits of the biosphere: "If we as human beings are to 'act from within nature', as the ethos of biomimicry implies we ought, then the requirement of recursiveness applies to us, to our agency. We must allow our ends as well as our means, our designs, to be shaped by who and what is out there in our environment" (Mathews 2011: 373). In this respect, the strong concept of biomimicry includes nature as normative principle of the conduciveness to ecological health and integrity as design principle, i.e. as a standard of ecological ethics, contrary to conceptualizations of biomimicry that exclusively look at these principles of nature in mechanistic terms (we come back on this conceptualization of biomimicry in a moment).

In order to adhere to natural principles as a normative standard of technology and design, however, mimicry has to be understood in the strict sense of an copying or an reproduction of nature. On the one hand, by copying or echoing the design principles of nature, our technological innovations can claim to be more 'natural' and to be more 'adaptive' to the capacities of the biosphere (Benyus 2002). On the other hand, our biomimetic designs can only claim to be ethically advantageous if they really have copied these natural principles. In other words, because biomimicry is understood in the strong sense as copy or reproduction of natural processes, Benyus cum suis can claim biomimicry to be bioinclusive and ethically 'right.'

There are, however, at least three presuppositions in this strong concept of mimesis in biomimicry, all three of which are questionable. First, a strong concept of biomimicry presupposes a strict distinction between the mere discovery of entities or systems that already exist-natural principles-, which are copied, and the invention of newly created things like artefacts, which are invented. This strict distinction is already questionable from an Aristotelian perspective, because mimesis concerns not only the imitation or reproduction of what is given in nature as we have seen, but also the supplementary perfection of what nature is not capable of producing itself. This difficulty in distinguishing between discovery and invention is also confirmed by Godin's (2008) history of the concept of innovation: The idea of novelty is indeed key in the concept of invention in contrast to the concept of imitation, but invention can be used both for finding and for making. Finally, if we acknowledge the theory-ladenness of perception (Popper 1974), we have to admit that every discovery, just like every invention, already involves a construction.

\footnotetext{
2 The assumption that natural principles conduce to ecological health does not imply that non-natural principles necessarily conduce to un-healthy eco-systems. It is principally possible to discover design principles that cannot be found in nature but nevertheless conduce to ecological health, and with this, it is principally possible to design technologies and innovations based on non-natural principles, which can claim to be ethically right. But this is not an argument against the claim of the strong concept of biomimicry that biomimetic innovations are ethically right. Proponents of a strong concept of biomimicry do not have to deny this possibility of a non-natural measure to judge the ethical rightness of technological innovations. They only argue that natural principles conduce to ecological health, and therefore, that biomimetic technologies and innovations can claim to be ethically right as well.
} 
A second presupposition of the strong concept of biomimicry is our epistemic sufficiency to 'know' the designs of nature; in order to 'echo the ideas of nature' or to 'borrow designs from the larger life system', we should be able to have full access to nature, to be able to understand and know the natural processes itself. It is questionable, however, whether natural processes are fully accessible and understandable for us. The complexity and temperamentality of natural phenomena limit the possibility of our discovering and then echoing nature's models to solve technological problems (cf. Bensaude-Vincent et al. 2002).

A third presupposition of the strong concept of biomimicry is a strict distinction between the technological intervention in nature-the exploitation of the first industrial revolution - and the pure receptivity of nature - the sensing and learning from nature of the second industrial revolution. If we acknowledge the complexity and temperamentality of nature, we also have to acknowledge the necessity to translate and interpret natural phenomena in order to explore their applicability in the context of technological problems. With the introduction of the concept of translation and interpretation however, the ethical advantage of biomimetical design becomes questionable, because a strict distinction between reproduction and invention can no longer be made.

Because of the questionability of these three presuppositions of the strong concept of biomimicry, we turn now to a weaker, but more sophisticated concept of biomimicry like that developed by Joanna Aizenberg, co-director of the Kavli Institute for Bionano Science and Technology at Harvard University. During a $\mathrm{TED}^{3}$ talk on March 5, 2012, she introduced biomimetics as a strategy "to mimic high-tech solutions that nature can give us, reformulate natural materials, natural strategies and to create new materials and devices that outperform anything that we have today" (Aizenberg Ted 2012). For the sophisticated concept of biomimicry, mimicry does not consist of the reproduction or duplication of natural solutions; rather, these natural solutions are taken as inspiration to create new materials and devices, or as Bensaude-Vincent et al. put it: "biomimetism ... is more a question of inspiration in the poetic sense, that is the intention of original forms or processes starting from a natural motive that solved a similar problem [by] either borrowing directly from living things, or mimicking nature's structures, function and processes..." (Bensaude-Vincent et al. 2002).

Contrary to the first presupposition of the strong concept of biomimicry, the weaker concept sees mimicry not as the duplication of natural solutions, but primarily as a creative solution inspired by nature (cf. Ball 2001). Contrary to the second and the third presupposition of the strong concept, the weaker concept acknowledges that "some form or procedure of interpretation or translation from biology to technology is required" (cf. Vincent et al. 2006). In the weaker concept of biomimicry therefore, the complexity and temperamentality of natural phenomena are acknowledged, as well as the necessity of translation in order to transfer natural problem solving to technological problem solving.

\footnotetext{
3 TED (Technology, Entertainment, Design) is a non-profit organization whose stated aim is to make great ideas accessible and spark conversation (www.ted.com).
} 
This raises the critical question of what happens to our hope for a new biomimetic approach to nature that no longer dominates and exploits nature if we embrace the weaker concept of biomimicry. Is there still a difference between traditional technology characterized by the exploitation of nature and biomimetical technology, if nature is no longer the model and ethical standard of our technological innovations, but is just understood in mechanical terms? What, in other words, is the difference between the first and the second industrial revolution if biomimicry is understood in this weaker sense of the word? The weaker concept of biomimicry cannot claim to imply a bioinclusive ethics like the strong concept of biomimicry. On the contrary, the weaker concept does not take natural principles as a normative standard, but focuses on the re-creation of nature for human ends. In the weaker concept of mimicry, nature is considered purely as a "storehouse of readymade designs available for us to mix and match to our consumer purposes" (Mathews 2011: 373), i.e., as a resource for useful ends and purposes (cf. Schyfter 2012). With the introduction of a weaker but more sophisticated concept of biomimicry, the specific advantages of biomimicry as learning from nature over technology as exploitation of nature threatens to fade away.

Before we can answer the question of which one of both types of biomimicry is suitable to be used in the second-biomimetic-industrial revolution, we compare them by critically reflecting on four dimensions of the concept of biomimicry in the next section: mimesis, nature, technology, and ethics.

\section{Strong- and Weak Biomimicry Compared}

\section{Mimicry}

As we have seen in the previous section, the concept of mimicry cannot be understood from classical oppositions like discovery versus invention. In the Aristotelian tradition, mimicry is not only the mechanical imitation of nature as it is discovered (nature as model), but also the aemulatio or perfection of this model, i.e., an 'invention' (poiesis). However, mimicry cannot be understood as an invention inspired by nature, because mimicry can only be an aemulatio or perfection of nature if it is in fact oriented on nature as model. The distinction between discovery and invention does not help to characterize the nature of bio-mimicry and seems to introduce a completely new category.

The French philosopher Lacoue-Labarthe has extensively reflected on the concept of mimesis (Lacoue-Labarte 1990, 1998). According to Lacoue-Labarthe, mimesis is not a completely new invention, because it perfects what is already in a certain way but what is not at the same time: nature. Why? If it already existed completely, it would not have to be perfected by a technological mimesis. So, on the one hand, mimesis mimics what already exists, and, on the other hand, it only exists in the strict sense of the word because of this mimicking activity of the techne.

Lacoue-Labarthe conceptualizes this relation between techne and phusis in terms of an original supplementarity (Lacoue-Labarte 1990: 58ff). The techne brings something new to the mimesis of nature, a supplement, and only this technological 
supplement provides access to phusis as the origin of the mimesis according to Lacoue-Labarthe, because a perfection of phusis by techne implies a deficiency of nature. Nature is deficient because it cannot produce everything and has to be perfected by technology. On the basis of Heraclitus' famous thesis that nature has the tendency to conceal itself, we can conceptualize this deficiency of the phusis as the tendency of nature to conceal itself, and therefore nature has to be supplemented by a technological re-presentation in order to appear for us (cf. Blok 2014a; Heidegger 2000). As such a re-presentation of phusis, the technological mimesis has to be understood as an addition or supplement to the original phusis. At the same time, this re-presentation is constitutive of our experience of the phusis. Because phusis has the tendency to conceal itself, only a technical supplement or representation of the phusis is able to give us access to this original phusis, according to Lacoue-Labarthe. Mimesis is therefore not only a reproduction of the original phusis but at the same time constitutive of this original. In this respect, LacoueLabarthe calls the techne and the phusis co-original (cf. Peperstraten 2005).

What this brief consultation of Lacoue-Labarthe's concept of mimesis already makes clear is that the concept of mimesis is theoretically underdeveloped in the current literature on biomimcry, but that its conceptual analysis could provide possible guidelines for future research in the field of biomimicry. The concept of supplementarity could, for instance, be helpful in biomimetic practices, because it can help us to reconsider the dichotomy between reception and discovery on the one hand and invention and intervention on the other. Biomimicry is then not the discovery of nature's model and the copying of natural processes in our technological designs, as is claimed by the strong concept of biomimicry. This perspective is highly naïve, because successful copying of nature is quite rare; the imitation of the wing of a bird for instance does not result in the ability to fly, as the history of aerodynamic techniques clearly shows (Vogel 1998). The question is, however, how such a supplementarity of the concept of biomimicry has to be understood in practice, and what the consequences are for the idea that biomimetical innovations are better embedded in, and in harmony with, the ecosystems of planet earth.

\section{Nature}

As we have seen already in "Introduction" section, the concept of nature which is presupposed in both the philosophical tradition and the literature on biomimicry is a technological model of nature; nature is understood in technological terms as productive and makeable. According to the strong concept of biomimicry, the production of nature is already perfect and should be reproduced in biomimetic technologies; the technologies of the first industrial revolution are imperfect and should be perfected by the second industrial revolution by mimicking nature. Mathews for instance argues: "If we as human beings are to 'act from within nature', as the ethos of biomimicry implies we ought, then the requirement of recursiveness applies to us, to our agency. We must allow our ends as well as our means, our designs, to be shaped by who and what is out there in our environment" (Mathews 2011: 373). At the same time, we have seen in "Biomimicry and the 
Conceptualization of Nature" section that the conceptualization of biomimicry as reproduction of nature is highly naïve and that all mimicry involves a supplement or re-production of nature's productivity. So nontheless the ambition of the strong concept of biomimicry to re-produce the perfection of nature, such a pure reproduction is highly naïve and also impossible, given the sup-plementary character of all mimesis. This supplementarity of mimetic reproduction seems to be better acknowledged in the weak concept of biomimicry. However, if mimicry is understood as a supplementary reproduction of nature, it logically follows that nature itself is no longer seen as perfect, but as im-perfect or deficient.

This deficiency of nature is not a new phenomenon related to the weak concept of biomimicry, but embedded in a long tradition from Plato to Nietzsche in which human technology is seen as a 'remedy' for the deficiency or biological incompleteness of our genetic and instinctive existence (cf. Nicolosi 2014). In this respect, biomimicry can even be conceptualized as an effort to surpass the limits of nature. One can even use the deficiency of nature as reason to reject a strong concept of biomimicry. If we conceptualize nature as deficient, a strong concept of biomimicry is no longer desirable because human technology should not mimic this deficiency but precisely develop a remedy for it. And this approach seems to be at stake in the weaker concept of biomimicry.

But do we have to accept this concept of the deficiency of nature? This raises the question of how the characteristics of both nature as productive and nature as deficient are related to each other in the weak concept of biomimicry. Is it because nature is understood as productive (poiesis) that it is automatically understood as deficient because it cannot produce everything? If we acknowledge that the deficiency of nature is the result of its conceptualization as productive (poiesis) nature is productive but deficient because it cannot produce everything-the question that arises is: Is nature still characterized in a negative way as deficient if we no longer think of nature as based on the model of technology? What is the essence of nature in general and what is the ontological status of the 'deficiency' of nature in particular? Is it necessary to conceptualize it negatively as deficient, or is it for instance possible to conceptualize it in more neutral terms as self-concealing (cf. "Biomimicry and the Conceptualization of Nature" section) or, in LacoueLabarthe's lexicon, in terms of the desistance of nature? Desistence originally means withdrawal or standing down, and the desistance of nature concerns both the self-withdrawal of nature as well as the being withdrawn of nature (cf. Derrida 1998; Martis 2005; Blok 2014b).

The concept of desistence could be helpful in biomimetic practices because it enables us to conceptualize and acknowledge the fundamental complexity and temperamentality of the natural processes that biomimicry is trying to mimic. On the one hand, such a neutral formulation of the desistance of nature leaves possible room for the strong concept of biomimicry. On the other hand however, the question for the strong concept is how to integrate this desistence of nature in our technological designs. Benyus, for instance, argues that it is not only product designs themselves that have to be borrowed from nature, but also the production processes and the infrastructure that facilitate this production (Benyus 2002; cf. Mathews 2011). It seems, in other words, that the weak concept of biomimicry has a 
greater flexibility in dealing with the question how the desistance of nature should be conceptualized and integrated in concrete biomimetic designs. As long as nature is understood on the basis of the model of technology in biomimicry however, it is not possible to think of nature qua nature, i.e., the ontological status of this 'deficiency' of nature.

\section{Technology}

On the one hand, the supplementarity of biomimetic technologies presupposes continuity between nature and technology, because it concerns the perfection of nature. On the other hand, it presupposes a discontinuity between nature and technology because it concerns the sup-plementing of nature. If biomimetic technology is essentially sup-plementary and cannot be reduced to nature, the ontological status of this supplementarity of technology is unclear. What is it exactly that is not natural in biomimetic technology?

One can argue that biomimicry is perhaps able to mimic an actual function of an organism or ecosystem - for instance a gecko's function of walking on the ceilingbut that, contrary to living systems, artefacts cannot mimic the adaptability of living systems to new possible circumstances resulting from changes in the environment. The supplementarity of biomimetic technology consists then in the fact that it copies a current and fixed function of an organism or natural system by taking it out of its spatiotemporal context and history. This would mean that the supplementarity of biomimetic technology consists in the re-production of natural phenomena without their specific spatiotemporal context and history, and will always be dependent on natural processes in order to find new possible functions that can be reproduced in a technological way. It is also possible to conceptualize the supplementarity of biomimetic technology in another way. If biomimetic technology copies a fixed function of an organism by taking it out of its spatiotemporal context and history, the supplementarity of this biomimetic technology could precisely consist in the production of a narrative with a new spatiotemporal context and history for our biomimetic technologies.

If one thing is clear, it is that the conception of the nature of the supplementarity of biomimetic technology has important consequences for our concept of biomimicry as such. On the one hand, the conceptualization of the sup-plementarity of biomimetic technology would limit the strong concept's claim to naturalness. On the other hand, the supplementarity of biomimetic technology would limit the weaker concept of biomimicry as creative solution as well, because this inspiration is heavily dependent on the dynamics of natural systems themselves. Is it still possible to maintain a strong concept of biomimicry if the sup-plementarity of biomimetic technology implies that it can no longer be seen as natural? Or is it possible to maintain a weak concept of biomimicry if the un-naturalness of biomimetic technologies may be supplemented by the development of a new spatiotemporal context and history for our technological designs?

The ambiguity of the discontinuity of nature and technology leads to the question: What is the ontological status of the supplementarity of biomimetic technology if it is not natural in the strict sense of the word? 


\section{Ethics}

We have seen that nature and naturalness operate as a normative standard to judge 'rightness' or 'naturalness' in the strong concept of biomimicry, because the principles are assumed to be principles that conduce to ecological health and integrity of the eco-systems of planet earth. We have to acknowledge that the strong concept has the advantage of being embedded in nature and in harmony with the natural ecosystems of planet earth, whereas the weaker concept can also be used to exploit and destroy nature. Nevertheless, a strict application of nature as measure in biomimetic practices is questionable. On the one hand, we have to admit that it is impossible to meet the requirements of Benyus' bioinclusive ethics because of the need to translate and interpret natural problem solving in order to transpose them to human problem solving, as we have seen. On the other hand, one can argue that nature as a measure to judge the ethical rightness of our technological innovations, is to commit the so-called naturalistic fallacy (Moore 1903).

According to Moore, the naturalistic fallacy consists in arguing that something is good because it is natural. It is more general than Hume's is/ought fallacy of stating a conclusion containing the copula ought derived from premises all connected by the copula is. While the weak concept of biomimicry avoids the naturalistic fallacy, the strong concept of biomimicry commits the naturalistic fallacy because it claims that technological innovations are good because they are based on principles of nature.

The proponents of a strong concept of biomimicry now can defend themselves by arguing that its normative component - the protection of the health and integrity of the ecosystems of planet earth-is independent of its descriptive component- the description of natural principles that conduce to ecological health and integrity; by mimicking these natural principles, biomimicry contributes to the protection of the ecosystems of planet earth without committing the naturalistic fallacy. Although this is a possible defence of the strong concept of biomimicry, it is in fact ambiguous, to say the least, because Benyus cum suis also suggest that the principles of nature are ethically good in themselves: "The biomimics are discovering what works in the natural world, and more important, what lasts. After 3.8 billion years of research and development, failures are fossils, and what surrounds us is the secret to survival. The more our world looks and functions like this natural world, the more likely we are to be accepted on this home that is ours, but not ours alone" (Benyus 2002: 3). Besides the risk of committing the naturalistic fallacy, the question can be raised as to what extent nature as that 'which lasts' can be claimed to be ethically good at all.

We can, for instance, argue that nature is the product of a struggle for existence. First of all, it is questionable whether the evolutionary measure of survival is a good measure for ethical behavior; we cannot claim that the fittest to survive are automatically the ethically good. Secondly, natural R\&D can be characterized as 3.8 billion years of zero tolerance processes of trial and error that resulted in beautiful natural designs - the fittest to survive-but also in enormous amounts of waste (cf. Zwiers et al. 2015). Human problem solving cannot afford this amount of waste and is in need of management practices that prevent the loss of generations 
and enhance ethical behavior. It can even be argued that ethics is contrary to the natural processes of the struggle for existence. Consequently, the transfer of natural $\mathrm{R} \& \mathrm{D}$ to the context of human problem solving is always limited by our ethical standards, and these ethical standards themselves are not primarily derived from nature (mimicry) but imposed on nature. This leads to the paradox that a biomimetic ethics is itself not ecological or natural. At the same time, several examples of biomimetic technologies, such as sustainable buildings inspired by self-cooling mounds of termites, strongly suggest that these types of technologies are better embedded in, and in harmony with, the ecosystems of planet earth. The risk of committing the naturalistic fallacy is therefore a formidable problem for the strong concept of biomimicry.

The ambiguity of nature as measure for the embeddedness of our technological innovations in the ecosystems of planet earth, and nature as a possibly unethical actor, raises the following question: To what extent is the bioinclusive ethics of biomimicry derived from nature or imposed on nature?

\section{Conclusions}

In this article, we have critically reflected on the concept of biomimicry. On the basis of an analysis of the concepts of nature and mimesis that constitute the concept of biomimicry and the philosophical origin of these concepts, we concluded, first of all, that both the Aristotelian tradition and current biomimetic research conceptualize nature in technological terms, i.e., as natural technology. Although the ambition of biomimicry is to mimic nature, it is in fact impossible to conceptualize nature qua nature. The conceptualization of nature qua nature is, however, important in biomimetics, because the difference between the first and the secondbiomimetical-industrial revolution threatens to fade away if biomimicry cannot claim to imply a bioinclusive ethics, i.e., nature as measure for the embeddedness of our technological innovations in the ecosystems of planet earth. The strength of the strong concept of biomimicry is that nature is seen as a measure to judge the ethical rightness of our technological innovations, but its weakness is found in three questionable presuppositions; (a) a strict distinction between the mere discovery of entities or systems that already exist-natural principles-, which are copied, and the invention of newly created things like artefacts, which are invented; (b) our epistemic sufficiency to 'know,' learn, and apply nature's designs; (c) a strict distinction between the technological intervention in nature- the exploitation of the first industrial revolution-and the pure receptivity of nature-the sensing and learning from nature of the second industrial revolution. These presuppositions are addressed by the weaker concept of biomimicry, but at the price that it is no longer possible to distinguish between an exploitative and dominating type of technology and an explorative and ecological type of biomimetic technology.

To determine which one of both types of biomimicry is suitable to be used in the second-biomimetic-industrial revolution, we compared both concepts of biomimicry by critically reflecting on four dimensions of the concept of 
Table 1 comparison between strong and weak concept of biomimicry

\begin{tabular}{|c|c|c|c|c|}
\hline & Mimesis & Nature & Technology & Ethics \\
\hline $\begin{array}{l}\text { Strong } \\
\text { biomimicry }\end{array}$ & $\begin{array}{l}\text { Naïve } \\
\text { conceptualization } \\
\text { of mimicry }\end{array}$ & $\begin{array}{l}\text { Presupposes } \\
\text { perfection } \\
\text { of nature }\end{array}$ & $\begin{array}{l}\text { Cannot deal with the sub- } \\
\text { plementarity of } \\
\text { biomimetic technology }\end{array}$ & $\begin{array}{l}\text { Risk of } \\
\text { committing the } \\
\text { naturalistic } \\
\text { fallacy }\end{array}$ \\
\hline $\begin{array}{l}\text { Weak } \\
\text { biomimicry }\end{array}$ & $\begin{array}{l}\text { Acknowledges sub- } \\
\text { plementarity of } \\
\text { mimicry }\end{array}$ & $\begin{array}{l}\text { Presupposes } \\
\text { desistence } \\
\text { of nature }\end{array}$ & $\begin{array}{l}\text { Cannot deal with the } \\
\text { supplementarity of } \\
\text { biomimetic technology }\end{array}$ & $\begin{array}{l}\text { Avoids } \\
\text { naturalistic } \\
\text { fallacy }\end{array}$ \\
\hline
\end{tabular}

biomimicry: mimesis, nature, technology, and ethics. Table 1 summarizes the results of our comparison:

From Table 1 we conclude that, from a philosophical perspective, the strong concept of biomimicry is more problematic than the weak concept of biomimicry. In all four dimensions the strong concept has major issues to resolve, while the weak concept has to deal with major issues in only two dimensions. Before we can answer the question whether the strong concept of biomimicry can be claimed to be a more 'responsible' or 'ecological' form of technological innovation or whether we should switch to the weaker concept of biomimicry, future research has to answer at least the following research questions:

(1) How should we understand the supplementarity of biomimicry in practice, and what are the consequences of the idea that biomimetical innovations are better embedded in, and in harmony with, the ecosystems of planet earth?

(2) How should the desistance of nature be conceptualized and integrated in concrete biomimetic designs?

(3) What is the ontological status of the supplementarity of technology if it is not natural in the strict sense of the word?

(4) To what extent is the bioinclusive ethics of biomimicry derived from nature or imposed on nature? ? $^{4}$

Open Access This article is distributed under the terms of the Creative Commons Attribution 4.0 International License (http://creativecommons.org/licenses/by/4.0/), which permits unrestricted use, distribution, and reproduction in any medium, provided you give appropriate credit to the original author(s) and the source, provide a link to the Creative Commons license, and indicate if changes were made.

\section{References}

Aristotle (1980). The Physics, trans. by Wicksteed, P. H. and Cornford F. M. Cambridge/London: Loeb Classical Library/Harvard UP.

Ball, P. (2001). Life's lessons in design. Nature, 409, 413-416.

\footnotetext{
${ }^{4}$ We would like to thank the reviewers of Journal of Agricultural and Environmental Ethics for their comments on an earlier draft of this article.
} 
Bensaude-Vincent, B., Arribart, H., Bouligand, Y., \& Sanchez, C. (2002). Chemists and the school of nature. New Journal of Chemistry, 26, 1-5.

Benyus, J. M. (2002). Biomimicry. Innovation inspired by nature. New York: Harper Perennial.

Blok, V. (2014a). Reconnecting with Nature in the Age of Technology. The Heidegger and Radical Environmentalism Debate Revisited. Environmental Philosophy, 11(2), 307-332. doi:10.5840/ envirophil20149913.

Blok, V. (2014b). Being-in-the-World as Being-in-Nature: An ecological Perspective on Being and Time. Studia Phaenomenologica, 14, 215-235.

Derrida, J. (1998). Desistance. In P. Lacoue-Labarthe (Ed.), Typography (pp. 1-42). Stanford: Stanford UP.

European Commission. (2012). Manifesto for a resource-efficient europe. (http://europa.eu/rapid/pressrelease_MEMO-12-989_en.htm).

Godin, B. (2008). Innovation: The history of a category. Working paper.

Hawken, P., Lovins, A., \& Lovins, L. H. (2000). Natural capitalism: Creating the next industrial revolution. Boston: Little, Brown \& Company.

Heidegger, M. (1999). Contributions to philosophy (from enowning), trans. by Emad, P., Maly, K. Indiana: Indiana UP.

Heidegger, M. (2000). Introduction to metaphysics, trans. by Polt, R. New Heaven \& London: Yale UP. Lacoue-Labarte, P. (1990). Heidegger, art and politics, trans. by Turner, C. Oxford: Basil Blackwell inc. Lacoue-Labarthe, P. (1998). Typography. Stanford: Stanford UP.

Martis, J. (2005). Representation and the loss of the subject. New York: Fordham UP.

Mathews, F. (2011). Towards a deeper philosophy of biomimicry. Organization \& Environment, 24(4), 364-387.

McDonough, W., \& Braungart, M. (2002). Cradle to cradle. Remaking the way we make things. New York: North Point Press.

Moore, G. E. (1903). Principia ethica. Cambridge: Cambridge University Press.

Nicolosi, G. (2014). On the traces of hephaestus. Skills, technology and social participation. Ph.D. Thesis, Wageningen.

Peperstraten, P. (2005). Sublieme Mimesis. Budel: Damon.

Popper, K. R. (1974). Conjectures and refutations. The growth of scientific knowledge. London: Routledge \& Kegan Paul.

Schyfter, P. (2012). Standing reserves of function: A Heideggerian reading of synthetic biology. Philosophy \& Technology, 25, 199-219.

Vincent, J. (2001). Structural biomaterials and biomimetic strategies. In C. Sanchez (Ed.), Biomimétisme et matériaux. Paris: OFTA.

Vincent, J., Bogatyreva, O., Bogatyreva, N., Bowyer, A., \& Pahl, A.-K. (2006). Biomimetics: Its practice and history. Journal of the Royal Society, Interface, 3(9), 471-482.

Vincent, J., \& Mann, D. (2002). Systematic technology transfer from biology to engineering. Philosophical Transactions from the Royal Society A, 360(1791), 159-173.

Vogel, S. (1998). Cat's paws and catapults. Mechanical worlds of nature and people. New York \& London: Norton \& Co.

Zwiers, J., Blok, V., Lemmens, P., \& Geerts, R. J. (2015). The ideal of a zero-waste humanity: Philosophical reflections on the demand for a bio-based economy. Journal of Agricultural and Environmental Ethics. doi:10.1007/s10806-015-9538-y). 